\title{
Adult-type granulosa cell tumor of testis: Case presentation
}

\author{
Abdullah Açıkgöz ${ }^{a *}$, Arzu Aydoğan Çilingirb ${ }^{b}$ Faruk Saltabaşb \\ a Department of Urology, Gazi State Hospital, Samsun, Turkey \\ $b_{\text {Department of Pathology, Gazi State Hospital, Samsun, Turkey }}$
}

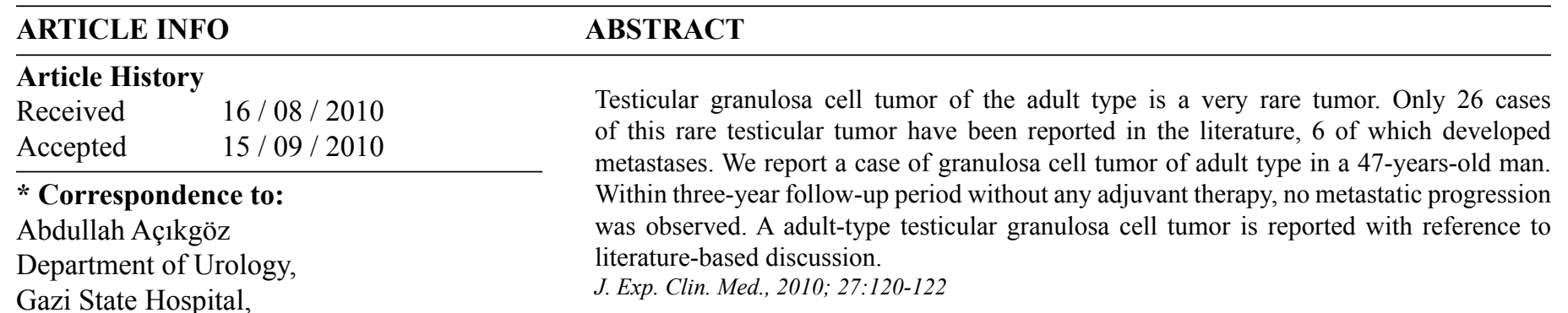

Ilkadim, Samsun, Turkey

e-mail:draacikgoz@yahoo.com

\author{
Key Words : \\ Granulosa cell tumor \\ Neoplasm \\ Testis tumor \\ Adult type \\ Sex-kord stromal tumor \\ Call-exner body
}

\section{Introduction}

Testicular granulosa cell tumors are among sex cord stromal tumors and they are very rare. There are two types of those tumors, including adult- and juvenile-type. Testicular granulosa cell tumors usually have benign prognosis. However, testicular granulosa cell tumors with metastasis are also reported (Marshall et al., 1977). Of 26 cases reported in the literature, 2 had only retroperitoneal lymph node metastasis, 1 had hepatic and retroperitoneal lymph node metastasis, 1 had pulmonary and another one had bone metastasis (Marshall et al, 1977; Matoska et al., 1992; Al-Bozom et al., 2000; Hammerich et al., 2008). Lack of experience due to low incidence of testicular granulosa cell tumors had led to failure to determine a standard treatment method. A adult-type testicular granulosa cell tumor is reported with reference to literature-based discussion.

\section{Clinical Case}

Forty seven years old male patient had applied due to complaint of swelling in left testis which had started two years ago, but increased severity within last 3 months. He was married. He has 1 son and 3 daughters. There was no history of systemic illness, infection, sexually transmitted disease, or urinary symptoms. The patient had had a stomach operation due to gastric ulcer 10 years before. The patient did not report any problems in testicular development such as cryptorchidism. In his physical examination, solid mass with dimensions of $3 \times 4 \mathrm{~cm}$ at upper pole of left testis could be palpated. There was no gynecomastia, endocrinrelated symptoms and erectile dysfunctions. Initial laboratory workup showed normal blood counts, liver function tests, kidney function tests, electrocardiogram, and chest radiography. Among testicular tumor markers following parameters and results were obtained; serum $\alpha$-fetoprotein: $2,56 \mathrm{ng} / \mathrm{ml}$, $\beta$ hcg: $<1,2 \mathrm{mIU} / \mathrm{ml}$ and LDH: 191 IU/1. In scrotal ultrasonography, solid mass with dimensions of $32 \times 26 \times 38 \mathrm{~mm}$ including cystic components at superior pole of left testis was observed in color Doppler ultrasonography. (Fig. 1) Due to this finding, patient was undergone left inguinal orchiectomy. In abdominopelvic and thoracic tomography performed for grading purposes with reference to result of pathologic study, there was a 2,5 cm simple cyst was present at lateral middle section of left kidney and no other findings indicating metastasis could not be found. 


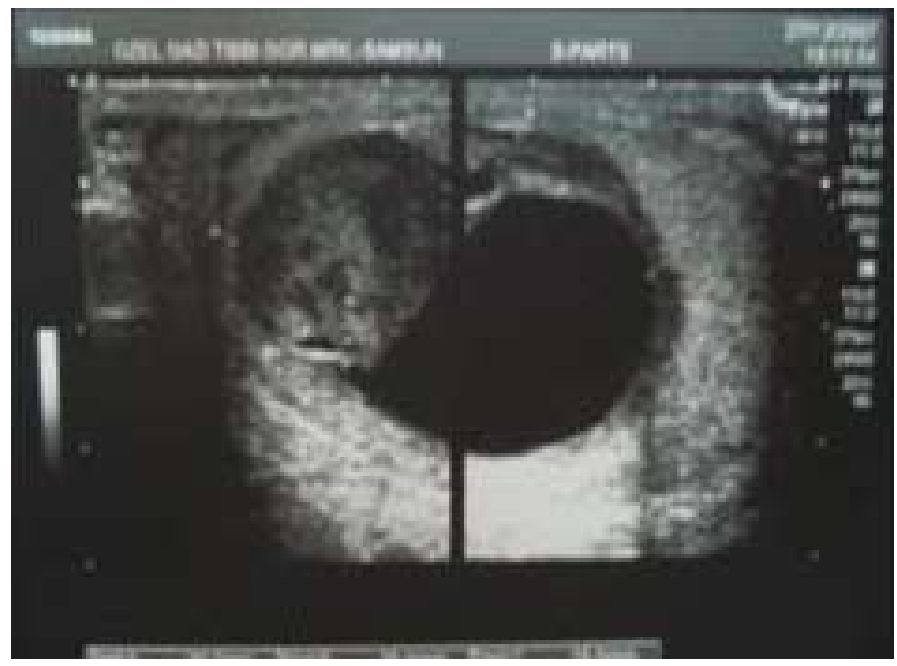

Fig. 1. The ultrasonographic iimage of the testicular mass

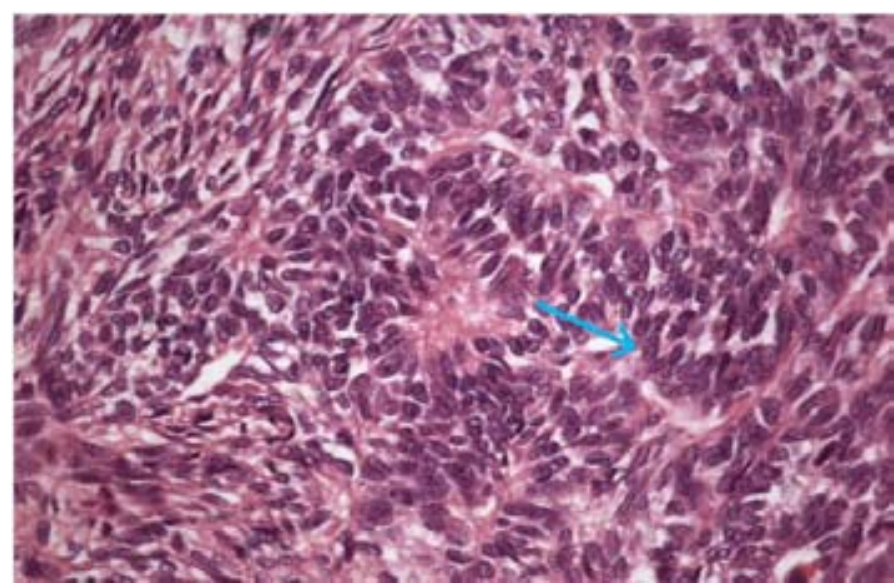

Fig 2. Granulosa tumor cell: oval nuclei cells with longitudinal grooves (coffee bean aspect) - arrow (HEx400)

\section{Pathological Findings}

The specimen consisted of left testis with attached epididymis and spermatic cord; the testis measured $6 \times 4 \times 3$ $\mathrm{cm}$ and weighed $40 \mathrm{~g}$. The upper pole of the testis was partially occupied by a tumor that measured $3,5 \times 3 \times 2 \mathrm{~cm}$ and formed a very well circumscribed unencapsulated spherical mass. The cut surface of the tumor was graywhite. Although presence of different structures with solid, trabecular and tubular growth patterns observed in histopathological examination suggested Sertoli cell tumor, dominant micro $\neg$ follicular structures and CallExner bodies, both typical for adult-type granulosa cell tumors, were found (Fig. 2-4). It was determined that lesion was restricted within testis and no invasion was present in tunica albuginea, rete testis, epididymis and spermatic cord as well as vascular structures. Three mitotic figures were found in microscopy in x10 magnification. In immunohistochemical examination, it was found that tumor was positively stained with Inhibin-A, but it was focal positive for cytokeratin (Fig. 3). On the other hand, placental alkaline phosphatase, CD30, a-fetoprotein and $\beta$ hcg stains were all negative.

Within three-year follow-up period, no metastatic progression was observed.

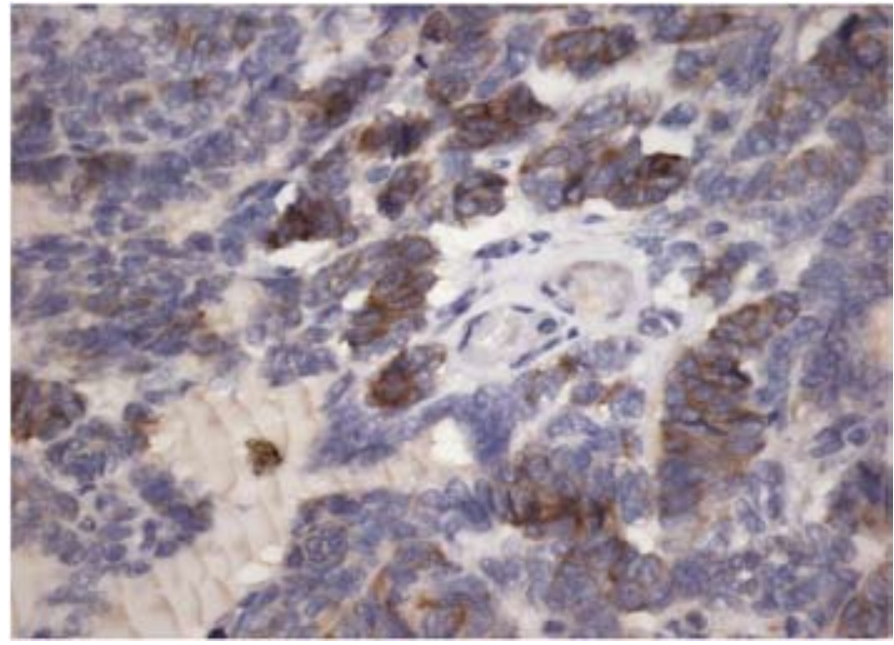

Fig 3. Immunohistochemically, the tumor was positive for inhibin-a (x400)

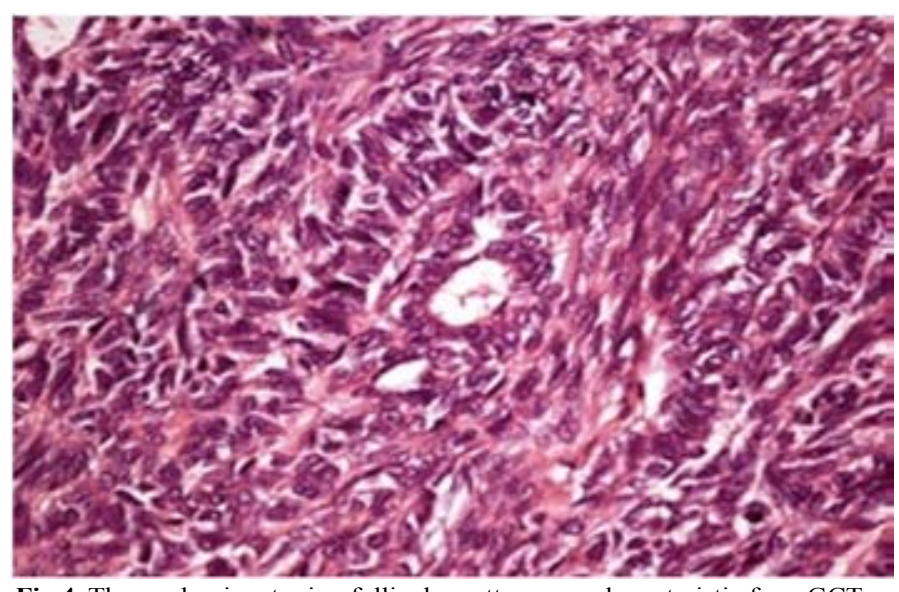

Fig 4. The predominant microfollicular pattern was characteristic for a GCT and typical Call-Exner-like bodies were present (HEx400)

\section{Discussion}

Adult-type granulosa cell testis tumor is very rarely observed and it accounts 4-6\% of all testicular granulosa cell tumors (Marshall et al., 1977; Al-Bozom et al., 2000). To date, totally 26 adult-type granulosa cell testis tumor cases were reported, since it was first reported by Laskowski in 1952 (Hammerich et al., 2008). It is usually seen at any of post-pubertal age groups and ages of cases range from 16 years to 77 years (mean: 43 years). As it is the case in other testicular tumors, it commonly causes painless testicular mass. Besides, gynecomasty and erectile dysfunction are also included, although rare, in admittance reasons of patients. The disease may have very slow clinical course (Hammerich et al., 2008). Thus, our case had recognized painless swelling in his left testis two years ago; however, he applied to our clinic due to significant increase in size of swelling within last three months.

Macroscopically, adult-type granulosa cell testis tumors appear as masses with yellow, gray $\neg$ white solid and cystic components having very sharp borders. Microscopically, those tumors involve different structures with solid, trabecular, tubular and microfollicular growth pattern. Those growth patterns and Call - Exner bodies attract attention, which are typically observed in hematoxylen eosin staining (Fig. 2). In diagnostic phase, 
value of immunohistochemicalstudiesis limited particularly in elder patients. Additionally, immunohistochemical markers are not useful for predict clinical course of the diseases. In many adult-type granulosa cell testis tumors, immune-positivity with vimentin, inhibin, smooth muscle actin and S-100 had been shown. Immunohistochemical studies were performed with other tumor markers such as leukocyte antigen, calretinin, CD99 as well as cytokeratin $\mathrm{AE} / 1$, although latter is scarce. Almost all tissue samples had negative staining with cytokeratin and epithelial membrane antigen. When tumoral tissue samples of our case were subjected to immunohistochemical examination, positive staining with inhibin, focal positivity with cytokeratin, placental alkaline phosphatase, CD30, a-fetoprotein as well as negative staining with $\beta$-HCG were found (Fig 3).

Sincehistopathologicaldiagnosiswasnotpreviously known, initial treatment was inguinal orchiectomy as in all testicular tumors. There is no standard treatment protocol in metastatic adult-type granulosa cell testis tumors as there is no adequate experience. Among cases reported in the literature, 6 cases were found to have metastasis at initial or follow-up period (Hammerich et al., 2008). Metastasis may also occur within long term following first diagnosis. Therefore, it is recommended to continue follow-up procedures in long-term basis following first diagnosis. Patients with lymph node metastasis have relatively good prognosis than patients with distant metastasis. No criteria predicting clinical course is known. Retroperitoneal lymph node dissection following inguinal orchiectomy, surgical excision of metastatic region, systemic chemotherapy (etoposide, cisplatin, bleomycine and doxorubicin alone or in combination) or radiotherapy have been applied in metastatic testicular adult-type granulosa cell tumors. (Hammerich et al., 2008; Matoska et al., 1992; JimenezQuintero et al., 1993; Suppiah et al., 2005). In our case, no metastasis had occurred within approximately one-year follow-up period.

\section{Conclusion:}

In conclusion, adult-type granulosa cell testis tumor is among very rare testicular tumors. It usually has benign properties, however, it can be clearly seen that it has metastatic potential. Long-term follow-up protocols should be applied due to ability of late metastasis.

\section{REFERENCES}

Al-Bozom, I.A., El-Faqih, S.R., Hassan, S.H., El-Tiraifi, A.E., Talic, R.F., 2000. Granulosa cell tumor of the adult type: a case report and review of the literature of a very rare testicular tumor.Arch. Pathol. Lab. Med. 124, 1525-1528.

Hammerich, K.H., Hille, S., Ayala, G.E., Wheeler, T.M., Engers, R., Ackerman, R. 2008. Malignant advanced granulosa cell tumor of the adult testis: case report and rewiew of the literature. Human Pathology 39, 701-709.

Jimenez-Quintero, L.P., Ro, J.Y., Zavala-Pompa, A., Amin, M.B., Tetu, B., Ordonez, N.G. 1993. Granulosa cell tumor of the adult testis: a clinicopathologic study of seven cases and a review of the literature. Human Pathology. 24, $1120-1125$.

Marshall, F.F., Kerr, W.S. Jr, Kliman, B., Scully, R.E. 1977. Sex cord-stromal (gonadal stromal) tumors of the testis: a report of 5 cases. J. Urology. 117,180-184.

Matoska, J., Ondrus, D., Talerman, A. 1992. Malignant granulosa cell tumor of the testis associated with gynecomastia and long survival. Cancer. 69, 1769-1772.

Suppiah, A., Musa, M.M., Morgan, D.R., North, A.D. 2005. Adult granulosa cell tumor of the testis and bony metastasis. A report of the first case of granulosa cell tumor of the testicle metastasising to bone. Urol. Int. 75, 91-93. 